\title{
Creativity and Culture: Nigerian Conceptions
}

\author{
Felix-Kingsley Obialo \\ University of Ibadan School of Business, University of Ibadan, Ibadan, Nigeria \\ Email: feking@yahoo.com
}

How to cite this paper: Obialo, F.-K. (2018). Creativity and Culture: Nigerian Conceptions. Creative Education, 9, 2863-2877. https://doi.org/10.4236/ce.2018.916215

Received: November 1, 2018

Accepted: December 24, 2018

Published: December 27, 2018

Copyright $\odot 2018$ by author and Scientific Research Publishing Inc. This work is licensed under the Creative Commons Attribution International License (CC BY 4.0).

http://creativecommons.org/licenses/by/4.0/

\begin{abstract}
Creativity is an inevitable phenomenon resulting in people's need to solve their problems. This phenomenon is captured differently by each culture's values and beliefs. Though Western conceptions of creativity dominate literature with an impressive contribution from Eastern cultural conceptions, African conceptions of creativity seem to be obscure. This article uses the three dominant Nigerian cultures namely Hausa, Igbo and Yoruba to underscore the relationship between culture and creativity. It contends that any concept of creativity is reflective of a people's cultural viewpoint. While communal and religious interpretations of the association are traditionally Nigerian, there is, however, a contemporary dimension to the Nigerian concept of creativity which is also Western in outlook. The result is an amalgam of the traditional Nigerian and Western conceptions of creativity in one socio-cultural setting called Nigeria. However, the fusion of these two cultural concepts does not rob the traditional Nigerian notions of creativity the enduring traits of what other cultures understand to be creative. Consequently, if the various cultural understandings of creativity have all led to growth and development in their different cultural settings, it behooves multiple stakeholders of the Nigerian society the duty and responsibility of promoting the prevailing conceptions of creativity from their cultural backdrop for the growth and development of the Nigerian experience.
\end{abstract}

\section{Keywords}

Creativity, Culture, Igbo, Yoruba, Hausa

\section{Introduction}

Creativity and culture are essential twins in the understanding of change and development. Creativity is associated with the way human beings confront change and growth. Culture, on the other hand, reflects a people's way of conceiving reality and that reality includes their attitude and principles about crea- 
tivity, change, and development. Since culture encapsulates a people's way of life, creativity becomes pertinent in such people's understanding and interpretation of their existence. Creativity is an essential life skill courted by individuals and corporate entities for the advancement of their experience (Puccio, 2012; IBM, 2010). It becomes pertinent therefore to study each people's conceptions of creativity from their cultural context. The work of Peng and Plucker (2012) revealed the cultural influence in the recent transformation of China's promotion of creativity and innovation with the top-bottom approach compared to the bottom-top approach prevalent in the American culture. In the former, the government is the catalyst of the culture of creativity and innovation, while the latter culture encourages individuals to initiate creative and innovative developments. Rudowicz (2003) submits that there is a reciprocal interaction between culture and creativity in such a way that creativity is not only influenced by culture, creativity in itself impacts how a culture develops and accepts creative products and ideas. Hondzel and Gulliksen (2015) found that culture and communities potentially shape the development of creativity skills among Norwegian and Canadian 8-year olds. For them "Creativity is then shaped culturally and socially, through interactions between the mind and behavior in a cultural space" (p. 2). Change is a constant fact of life. Creativity becomes inevitable for the improvement of the human condition which is consistently changing. Creativity is needed for sustainable growth and development in every civilization and has been exhibited in varying degrees by peoples and cultures since the advent of creation (Puccio, Cabra, \& Schwagler, 2018). The question then arises: Why do some cultures inspire change and creative skills which take care of the change, while others seem to be intolerant of creativity? Additionally, what type of creativity is accepted? If different cultures react differently to creativity, it suggests that cultures would equally influence creative expressions differently. No wonder Ludwig (1992) asserted that the relationship between creative and cultural expression was powerful and complex. For him "Culture exerts a profound effect on creative expression. Not only does it influence what is expressed, but it also determines by whom it is expressed, how it is expressed, and what functions this expression serves" (p. 454). The interface between the individual, cultural, and social systems bring transformation to society, and it is the sociocultural environment that influences what and how ideas are expressed (Rudowicz, 2003). Sociocultural environments differ. It is possible to differentiate the different cultures of the world into African, Western, Asian, Latino and Arab cultures. Each of these cultures has general characteristics. However, there are peculiarities.

This work begins on the foundation that all cultures produce creative expressions in one way or the other. Despite the dominance of Western conceptions of creativity which has inspired the promotion of Eastern concepts of creativity, African conceptions of creativity seems to be muffled. Therefore, this article, aims to add to the increasing effort to present an African dimension to the understanding of creativity by presenting viewpoints from Nigeria. The concern of 
this work is a variant of the African Culture, Nigerian culture. Its peculiarity within the gamut of African culture presents it as a potential model for understanding the African dimensions of creativity and ultimately what it can contribute to global understanding of creativity. The case is made, therefore, for increased cross-cultural studies of the association between creativity and culture. This position is consequent on the various types of crises that contemporary society is facing some of which are rooted in cultural biases that are, unfortunately, taking humanity back to the dark ages and as such stifling creative expressions.

\section{Culture and the Nigerian Experience}

As long as people collect and begin to share their lives together, cultures develop with time. Culture becomes the totality of their experiences becoming a stable phenomenon. Consequently, culture refers to "the rules and habits that bind a particular society together...the set of practices that keep a society together and allow its members to find meaning in their lives" (Baldock, 2010: p. 2). Culture confers a unique identity on people who practise this set of behaviors. Since culture defines people, the cultural identity that someone develops will be an adaptation to the conscious and unconscious circumstance of the person (Baldock, 2010). Such circumstances have foisted on the average Nigerian a dual culture. The first is the ancient culture the average Nigerian like other Africans were born into. The other is a modern culture that has become the lot of the African as a consequence of colonialism and westernization. Accordingly, for the Nigerian, one must speak of a tale of two cultures for a comprehensive understanding of their contemporary cultural identity. The totality of the Nigerian experience to date would lead one to also talk about a culture within a culture. The modern Nigerian is thus a multicultural person.

\section{Traditional versus Contemporary Nigerian Culture}

Traditional Nigerian culture could be described as one that included those primordial practices which defined different groups of people inhabiting the political territory now called Nigeria. These groups currently constitute tribes and ethnic groups namely the Hausa, Igbo, Yoruba, Ijaw, Urhobo, Kanuri, Igala, Idoma, Tiv, Ibibio, Anang and Itshekiri among others. The largest groups, however, are the first three. With a population of between 176 and 180 million, it is believed that Nigeria has more than 250 ethnic groups (Mberu \& Pongou, 2010). The cultures of these groups are identified by traditional dances, religious rituals, pottery, arts, myths and superstition among others. A feature of these rules and habits that bind Nigerians together is that the average Nigerian still believes and practices them albeit in varying degrees. It is a fact that the ever-evolving contemporary culture complements traditional Nigerian culture. This has given rise to a culture that could be referred to as modern Nigerian culture. However, it must be noted that the two mutually influence each other. Hence, we conclude that the average contemporary Nigerian is multicultural. We have to emphasize 
average because we have some Nigerians who are still not too exposed to modernism and modern culture. There are also those who could be described as wholly weaned from traditional cultural influences.

\section{Traditional Nigerian Notions of Creativity}

Despite the fact that since the dawn of humanity, people have always used their imaginations to solve problems creatively; human beings have taken their creative thinking for granted (Grivas \& Puccio, 2012). Chism-Peace (2008) and Etuk (2007) explaining the nature of creativity assert that creativity is a fundamental capacity and endowment of the human mind. The field of creativity practice and study have re-enforced this fact over the years (Obialo, 2017). Unfortunately, humanity has continued to limit itself by not exploiting its creative capabilities to the full. The above reality leads us to explore the definition or meaning of creativity.

The understanding of creativity has undergone some exciting transition through years of research and practice (Runco \& Albert, 2010). This development has occasioned several definitions of creativity prompting Smith (2005) to declare that we are still far from completely comprehending what creativity is. Years back, Rhodes (1961) concluded that the various definitions of creativity were efforts to understand creativity from the four P's (person, process, press (climate) and product. These four perspectives of looking at creativity have persisted till date. Further, Puccio (2012) stated that it is commonly accepted that creativity is the production of something novel and useful. Among researchers and writers in the field, creativity is popularly defined as "a process that leads to the production of original ideas that respond to a perceived problem or opportunity" (Puccio, Mance, \& Murdock, 2011: p. xvii). It would seem that Rhodes' (1961) conclusion about the four P's of creativity provided the bedrock for a better understanding of creativity. In that sense, we could also state that different conceptions of person, product, press, and process of any phenomenon like creativity would always colour people's idea of creativity in any cultural setting. The above leads us to the Nigerian multicultural contextual notions of creativity.

One overarching fact of the African is religiosity. This reality prompted Mbiti (1969) to declare that the African is in all things religious. Just like ancient Westerners (Runco \& Albert, 2010), traditional Africans see creativity as resident in the divine who is the Almighty, the Ultimate Creator (Obialo, 2017a). Different ethnic/cultural groups give the Divine/Almighty various names. Traditional Nigerians like other Africans ascribe all forms of creativity to divine activity first and foremost. This work shall mostly refer to the Divine, the Almighty as "God." Consequently, those who create like potters, sculptors and artists are seen as specially favored by the Divine or the gods because they are participating in divine activity (Mbiti, 1969; Onwubiko, 1991). This group believed to be divinely gifted, at times is saddled with producing artistic works for religious worship (Onwubiko, 1991). Creativity thus is a privilege gift from the Divine. The above 
brings us to the Nigerian idea of creativity.

Mpofu et al. (2006) have described African society as transitioning. If that is the case, there must be some remnants of traditional African cultural values which would be transferred to modern or contemporary times. In the same token, the two cultures practised by the same people would have effects on each other. This belief holds true for Nigerian culture and psychological concepts in the contemporary sense. To understand any concept in any traditional or transitory society such as Africa, one must first determine if there exists any word or its equivalent in that cultural or linguistic setting that conveys the concept. Every linguistic or cultural expression encapsulates a people's understanding of ideas that convey meaning to them. Such theories also reflect their past, present, and future realities. That leads the discourse to the issue of Nigerian expressions for creativity. Examining Nigerian expressions would help to expose the people's comprehension of what the idea of creativity means to them. So far, this work has established the fact that there are many tribes and ethnic groups in Nigeria. However, there are three major tribes that seem to dominate discourse about Nigeria. Consequently, this current effort at establishing the relationship between creativity and culture from the Nigerian perspective examines the understanding of creativity from the three major tribes, cultures or languages of Nigeria namely Hausa, Igbo and Yoruba. This is because language conveys the meaning of concepts or experiences of a particular people. As Nabi (2017: p. 91) asserts, "The meanings of a particular language represent the culture of a particular social group. To interact with a language means to do so with the culture which is a reference point".

In their work, Mpofu et al. (2006) claimed that there is only one language (Arabic) which has a word that directly translates to creativity in Africa-ibda. From this word comes bid'a which means innovation. They also affirmed that there have been creative products all over Africa for millennia citing the Great Pyramids of Egypt and the Igbo Ukwu arts of Nigeria among others. One then wonders what the creators and societies of these novel and useful monuments and artefacts. The positions of Mpofu and his colleagues are somewhat conflicting and leaves ample room for dissent. Aristotle once said, "What is honoured in a culture will be cultivated there" (cited in Torrance, 2003: p. 277). If the ancient African civilizations referenced by Mpofu and his colleagues created these products that are still reference points in contemporary discourses, they must have valued creativity. In essence, these cultures valuing creativity nurtured and practised it. Any people who identifies a phenomenon would usually acknowledge such a phenomenon by inventing a name or label for it. No matter how such people conceive such a phenomenon they must not be denied the reality of such an experience.

In traditional Nigeria, creativity has several expressions in the three major languages mentioned earlier. If it is agreed that language is the means of communicating people's experiences, and creative expressions are established to be creative after subjecting such outputs to criteria for determining what is creative, 
it is incontrovertible to conclude that the cultures in which these products are domiciled would necessarily have the language or terms to communicate them. These terms could be single or groups of words. As such, it would seem dangerous and unfair to use other standards to judge other cultures' creative outputs (Kim, Mishra, Hinds, \& Liu, 2012). This is because creativity is defined differently by different cultures (Lumbart, 2010; Kim et al., 2012). If the same criteria are used to judge creativity in different cultural contexts, then the documented fact that creativity is defined differently by various cultures would be redundant. This fact is especially true in cross cultural inquiry.

Further, Lubart (2010) identified four approaches that allow for the study of conceptions of creativity. The first is to allow people in diverse cultural settings to define creativity in their culturally appropriate manner. Again people could nominate instances of creativity in their cultural contexts and the common characteristics examined. The third approach is for people to indicate individual or social variables that are features of creative people or creative achievements. The last is to ask people to assess a set of works, and their evaluation of creativity can provide insight into the criteria used to judge such works implicitly. The above accords Nigerians the right to tout their cultural notions of creativity. The four delineations are captured in the expressions of creativity present in the three major languages of Nigeria. These languages are cultural expressions of the experiences of these three major ethnic groups in Nigeria concerning creativity. Consequently, this work presents Nigerian cultural contributions to the creativity and culture discourse.

Creativity in the sense of being artistic would be expressed as fasaha in Hausa. D. Danjibo, senior lecturer, Institute of African Studies, University of Ibadan, Nigeria, explained:

Fasaha is often accompanied by another word-basira used as a suffix. So you have statements like Mai fasaha ne don ya na da basira. He is inventive, creative or innovative because he is intelligently/wisely gifted. Another word that connotes creativity in Hausa is hikima, which denotes creative inspiration. As such, we have expressions like Ya na da hikima a tsarin kimi'a. He has the inspiration for technological design. The third word concerning creativity is azanci that means coordinates innovation or diligence. Thus, you can say Ta na da azanci wurin adana abubuwa. She is creative in arranging/constructing things. Or Ya na da azanci wuring gina ginai that translates to $\mathrm{He}$ is creative in building things. The three words fasaha, hikima, and azanci are often used interchangeably both traditionally and in the contemporary sense. (Personal communication, December 7, 2017)

The Igbo understand creative production as both divine and human. D. Agbarakwe, an Igbo community leader, expanded:

Creativity is distinguished from a combination of words built on the verb ikwa- "to make/produce/to bring about." Ikwa is qualified with $n k a$ which means "something exceptional/extraordinary/better." Thus, creativity trans- 
lates to ikwanka which is a reference to the production of something unique, uncommon or novel. Further, there is a technological or innovative dimension to the Igbo notion of creativity. The products of artists, potters, blacksmiths and the like are the outcomes of ikwanka na uzu implying the production of novel things in the area of equipment production or even artistic expressions. (Personal communication, November 20, 2017)

In that wise ikwanka translates to the production of something that is beautiful and useful for particular purposes such as the ornamental, artistic, household needs, etc. However, the ability to produce something uncommon is perceived to be a special gift from God. It is also seen as hereditary. Consequently, creativity is a special privilege residing in some individuals and families who are fortunate.

P. Asawale, a Catholic priest and an expert in Yoruba language and culture asserted that:

The Yoruba would describe creativity as atinuda or iseda. The keyword is the verb $d a$ "create." However, creativity in this context has a spiritual connotation. It is creating after the example of God who is Aseda. Aseda has its root in Eledaa who is God himself, the creator of all that is. That is why God is referred to as Akoda Aye, Aseda Orun. i.e., the creator of the world and the heavens. To be called Aseda, therefore, is to be equated with God in the act of creation or creativity. Atinuda also is the art of creating what has never been in existence. Thus, the maker creates from within without having recourse to anybody or anything. It portrays an idea or an article as being original or new. Iseda is the art of Aseda. It is what Aseda himself does or creates. Consequently, aseda nnkan is the one who creates something. So the human being who creates is seen as aseda nnkan bayii. That is the creator of such and such a thing. The art of this "creator" is in Yoruba cosmology known as "ogbon iseda alatinuda" that is, the wisdom of bringing forth internally from that (person) creator. (Personal communication, December 2, 2017)

A common theme in the above conceptions/terms for creativity is the production of something different from what previously existed, whether the inspiration for the production is ascribed to man, the divine or God. Further, there is an overarching influence of the divine or religious in the above delineation of creativity from the Nigerian cultural and linguistic contexts. This position justifies Mbiti's (1991) assertion that the African is very spiritual in so many ways. Yet, the religiosity in the understanding of creativity does not rob the tripartite cultural understanding of creativity in Nigeria from the following universal understanding of creativity. That is, the Hausa, Igbo and Yoruba perspectives of creativity unite with the universally accepted notion that the core defining features of creativity are novelty, and appropriateness (Niu \& Kaufman, 2013). Further, the resort to the Divine in explaining creativity could be understood from the sense of wonder which novelty evokes in all peoples and cultures. This 
throws up a challenge before every culture which must strive to explicate their understanding of creativity to other culture in order to celebrate humanity's common heritage as a being endowed with creative capacities and abilities. Further, Csikszentmihalyi (2005) maintained that the only way to establish an understanding of creativity is through comparison, evaluation, and interpretation within and among cultures.

\section{Contemporary Nigerian Understanding of Creativity}

Like every other evolving culture, Nigerian culture is not exempt from outside influence. That is why this paper took the position that the average Nigerian is a multicultural person. The average Nigerian is thus living in a mutually influencing twin cultures of the traditional as well as the modern. Further, the fact of modern life means that communities are currently more connected than before making cultural connectivity to become an essential part of daily living (Yip, 2014). Mpofu, Myanbo, Mogaji, Mashego, and Khallefa (2006), reported that the sample for their work: "African Perspectives on Creativity" defined creativity in so many ways. These definitions they themed: "innovative, adaptive, personal agency, integrative, incremental, social impact oriented...domain specific, mystical, and imitative" (p. 466). The sample they reported, included participants from Nigeria. A quick look at these themes suggests a lot of modern influences. One notices that the traditional concept of creativity that is overly metaphysical becomes less dominant. It gives way to other schools of thought championed by Western experts and practitioners of creativity (Kirton, 1989; Sternberg, 2003; Runco, 2007; Amabile \& Kramer, 2011). One is forced to query what gave rise to this development? The answer is not farfetched as the following exposition will prove.

As Mpofu et al. (2006) reported, the study of creativity in Africa is a very recent phenomenon. The exposure to westernization has made western values readily available to a significant percentage of Africans including Nigerians. This influence is further accelerated by acceptance of Western education that now exposes everyone to values and concepts like creativity. Creativity seems to have become a favorite word. Whether those who hype the word understand and promote creativity is another matter to consider. In that sense, we look for some understanding between the old and the new notions of creativity in the Nigerian cultural setting.

In spite of the modest gains made so far in understanding the concept of creativity in modern Nigeria, there still exist some ancient cultural influences. A typical notion carried over from the traditional idea of creativity is the belief that creativity belonged to the supernatural or divine. However, the traditional position has been repackaged. Some Nigerians now attribute creative ability to a special class of people. This primordial idea is so prevalent that people still perceive those who are creative as possessing special skills that must be taken care of in particular ways (Oluseyi \& Olujide, 2014). One could, therefore, suggest that creativity in Nigeria is easily understood from the perspective of Big " $\mathrm{C}$ " or 
eminent creativity conception (Kaufman \& Beghetto, 2009). This way of conceiving creativity celebrates creativity as specifically given. Consequently, only very few people are and could be creative. Any Nigerian interested in creativity can appreciate the elitist perspective of creativity preferred by both ordinary and sophisticated people. This perspective is rooted in the Nigerian love for grandeur. This love is captured in the Nigerian knack for values such as titles, positions, and celebrations. Accommodating little "c" creativity (Kaufman \& Beghetto, 2009) is usually tricky within such view of creativity. This mindset about creativity would seem to have found official patronage with the development of the gifted education policy in the country. The policy was consequent on the need to provide some different and specialized education for those regarded as exceptionally talented (Federal Ministry of Education Nigeria, 1986). Thus, a school (Suleja Academy) was established by the Federal Government of Nigeria at Suleja, Abuja the nation's capital with the motto: creativity and excellence. (Federal Government Academy Suleja, 2018)

(http://www.fgasuleja.com.ng/index.html). Whether the objective of training creative or gifted students is being achieved is a different issue altogether.

The above misconception and political connivance notwithstanding, there are now departments in some universities across Nigeria providing students and researchers opportunities to carry out studies that would expose them to latest researches in global creativity studies. This development has ensured that creativity research in Nigeria is gradually shifting. It is moving from educational interests especially primary and secondary education (Nwazuoke, 1989; Olatoye \& Oyundoyin, 2007) to other areas of interests. There exists now creativity researches in other areas of human activities such as workplace, family, corporate world, university education, church and specialized groups (Akinboye, 2003; Obialo, 2011; Obialo, 2018). Western cultural influences have come to stay in Nigeria. Nigerian researchers in creativity are now being influenced mostly by western ideas and concepts in various areas of their work. However, there is a serious need to begin to look inward and develop Nigerian traditional, and contemporary experiences of creativity like the Eastern/Oriental researchers are doing. Such efforts would help to take advantage of the multicultural Nigerian setting in order to grow the sociopolitical, economic and technological life. Nigerian researchers can also learn from the Chinese top-down approach to utilising creativity and innovation for national development (Pang \& Plucker, 2013). Such an interest will also help to contribute the Nigerian experience to the global gamut of creativity research and understanding. It is pertinent to note that a significant practice that creativity research in Nigeria holds dear is to ensure that measures adopted or adapted from other cultures are evaluated for culture-fairness. Researchers are also encouraged to learn how to design valid and reliable tests in creativity (Obialo, 2011).

\section{West Meets Nigeria: Proof Creativity Is Universal}

Creativity literature continues to demonstrate the dominance of Western culture 
in creativity research and practice (Niu \& Kaufman, 2013; Kim et al., 2012; Runco \& Albert, 2010; Lubert, 2010; Mpoya et al., 2006). One must acknowledge the pioneering contributions of the West towards contemporary creative studies. It is also proper and right to recognize the fact that the groundbreaking effort of the West has been an invaluable contribution towards contemporary global creativity studies. The lesson, therefore, is that the West has utilized her cultural values to the benefit of the field of creativity research. It is, therefore, a challenge on the part of other cultural blocks to contribute to the wealth of creativity investigation from their cultural identities. Previous studies have shown that culture impacts the ways in which creativity is defined, and conceptualized (Klausen, 2010). Further, the dominance of Western cultural concepts in creativity research means that other cultural blocks would be exposed or forced to learn these concepts. In fact, they might also begin to conceive creativity from Western perspectives. Nigeria is, therefore, highly influenced in her current investigations into the construct by Western concepts (Mogaji, 2004). This influence has translated into the prevalence of creativity researches done in Nigeria from Western conceptions. This meeting between Nigerian cultural creativity perspectives and Western concepts of creativity has produced some beneficial results. It must quickly be added that beyond any reasonable doubt, that the meeting is auspicious. This is because it affords Nigerians the prospect of re-assessing their cultural concepts of creativity so as to use the gains of the past to improve their lot in their contemporary existence. Again, it is an opportunity to sell the benefits of their cultural notions of creativity to the world. This meeting makes multicultural exchanges possible in the global village. This cultural perspective permits us to conceptualize better the innumerable ways the environment can influence how creativity is expressed and experienced in creativity research (Hondzel \& Sorebo, 2015).

The above leads us to what is the predominant idea of this influence and what is in it for the Nigerian experience? Literature largely agrees that the Western notion of creativity is individualistic while Eastern and African concepts take communalistic approach (Kim et al., 2010; Lubart, 2010; Mpofu et al., 2006). These approaches naturally reflect the natures of the three cultures. For instance, African cultural values are community-based. Within that African context, the goodness of any action is judged in relationship with how it promotes the common good. The common good is determined by the Divine who provides rules for rituals and practices which preserve the society. Since God is the one who holds the community together, every person defers to the wishes and well-being of the society and the divine force which keeps the society together. No one goes against the wishes of God. This consciousness of the Divine informs all decisions and activities. Thus, if creativity is resident in the Divine, it must be exercised in line with God's will to preserve the community. Consequently, "I am because we are" (Mbiti, 1969). Since all actions are informed by the common good ordained by the Divine, it will not be safe to assert that the contextual characteristic of what is labeled creative is inherent in the communal acceptance of what is crea- 
tive within the general Nigerian culture.

One of the essential characteristics of what is creative is the context in which a creative action occurs. A lot of studies have revealed the integral role played by contextual factors in either stifling or promoting creative expressions in individuals, families, groups, workplace, communities and the like (Amabile \& Kramer, 2011; Glaveanu, 2013, 2014; Carlen, 2016). If the African and Nigerian conceptions of creativity also involve comunal considerations, care must be taken to delve more into the implications of this community involvement in undrstanding what is creative. The implications would undoubtedly have contemporary relevance especially in a Nigerian context that is simultaneously heavily influenced by Western cultural values.

However, the communalistic notion of creativity in Nigerian culture does not negate the universal characteristics identified with what is regarded as "creativity." These characteristics are novelty and usefulness. Novelty exists in the Igbo word nka, Hausa words fasaha, hikima and azanci and the Yoruba word iseda. The useful or pragmatic feature of creativity is captured in the Igbo expression ikwanka na uzu. This statement, one may explain as "the exceptional and the practical" as in the production of novel items for artistic or technological purposes among others.

The foregoing delineation brings us to the encounter between Western cultural influences and Nigerian culture. There is the issue of what yields to what? There is also the question of what could be mutually borrowed? One might also add the challenge of the possibility of a uniform global conception of creativity. In spite of these and other difficulties, it must be noted that the encounter is a mutually beneficial one. The challenge of this encounter between the West and Nigerian culture currently motivates Nigerians in various walks of life to investigate how the gains of creativity can improve the Nigerian experience. For instance, there are creativity courses in many higher institutions of learning in $\mathrm{Ni}$ geria. A number of creativity studies have also delved into areas other than primary and secondary education such as educational policy shift (Emeke \& Obialo, 2010; Obialo, 2017b), artisans (Mogaji, 2004) and prisoners (Animasaun, 2002). The above demonstrates one indubitable fact that creativity is a universal phenomenon.

\section{Conclusions}

If each culture has its understanding of creativity, there are possibilities of cross-cultural understanding of creativity. This knowledge will ensure respect for all cultural conceptions of creativity and their originators. Since the global economy is now a creative economy, cross-cultural understanding of creativity will build synergies among peoples. This collaboration will facilitate peace and harmony among the different peoples and cultures of the world. One huge lesson from the Nigerian experience is that while it met the West, it did not jettison its traditional conception of creativity but refined and borrowed from it. 
Cross-cultural collaboration does not lead to loss of identity but mutually augments the participating cultures. If creativity is to become relevant in the contemporary world, cultural influences which have become an integral part of modern man must be factored into understanding the construct. In the same token Nigerian authorities and creativity researchers must consciously understand the cultural gifts inherent in their creativity either from the traditional or contemporary conceptions of creativity. No man or cultural block is an island. This fact of people's dependence on one another is strengthened by the collaboration between the East and the West in the field of creativity. Nigerian creativity experts and practitioners must reach out to other cultures in order to exploit the advances made by them for the improvement of the Nigerian condition. As it stands, the idea of what creativity indeed is seems to be unpopular among average Nigerians. Yet, creative expressions abound in the country. If not for the spirit of creativity expressed in various aspects of the Nigerian life, the survival of the Nigerian citizen in the midst of decades of bad socioeconomic and political mismanagement would have been an impossible task. This creative spirit undoubtedly is a combination of the old and the new understanding of the human capacity to survive. It is therefore absolutely necessary to promote and actualize the potentials of the Nigerian creative spirit through study and practice.

Further, the relationship between culture and creativity challenges Nigerian stakeholders like governments, researchers, policy makers, the corporate world and individuals to deliberately nurture the traditional and contemporary cultural conceptions of creativity for the growth and development of the Nigerian society as the Western and Eastern societies have successfully done. The Western and Eastern notions of creativity have proved beyond any doubt that each culture, even when taken individually, can still promote creative living. Nigerian stakeholders are to, therefore, utilize the prevailing trado-modern conceptions of creativity for the nation's contemporary exigencies.

\section{Conflicts of Interest}

The author declares no conflicts of interest regarding the publication of this paper.

\section{References}

Akinboye, J. O. (2003). Creativity, Innovation and Success. Ibadan: CYFO Behaviour Services Ltd.

Amabile, T., \& Kramer, S. (2011). The Progress Principle: Using Small Wins to Ignite Joy, Engagement, and Creativity at Work. Boston, MA: Harvard Business Review.

Animasaun, R. A. (2002). Effectiveness of Six Thinking Hats and Practical Creativity in Fostering Positive Life Skills among Convicted Adolescents in Two Nigerian Prisons. Ph.D. Thesis, Ibadan: University of Ibadan.

Baldock, P. (2010). Understanding Cultural Diversity in the Early Years. Los Angeles, CA: SAGE Publications Ltd. https://doi.org/10.4135/9781446288108

Carlen, J. (2016). A Brief History of Entrepreneurship: The Pioneers, Profiteers, and 
Racketeers Who Shaped Our World. New York: Columbia University Press. https://doi.org/10.7312/carl17304

Chism-Peace, Y. (2008). Can Creativity Be Fairly Assessed? Teaching Is a Life Sentence. http://www.iwilla.com/essays/hungjury/evalcreat.htm

Csikszentmihalyi, M. (2005). Creativity: Flow and the Psychology of Discovery and Invention. New York, NY: HarperCollins.

Etuk, E. (2007). The Right to Be Creative: A Global Imperative. Paper Presented at Creative Problem Solving Institute (CPSI), International Conference on Creativity, Atlanta, Georgia. June 2007.

Federal Government Academy Suleja, 2018. http://www.fgasuleja.com.ng/index.html

Federal Ministry of Education Nigeria (1986). Blueprint on Education for the Gifted and Talented Persons. Lagos: Government Press.

Glaveanu, V. P. (2013) Rewriting the Language of Creativity: The Five A's Framework. Review of General Psychology, 17, 69-81. https://doi.org/10.1037/a0029528

Glaveanu, V. P. (2014) Theorising Context in Psychology: The Case of Creativity. Theory \& Psychology, 24, 382-398. https://doi.org/10.1177/0959354314529851

Hondzel, C. D., \& Gulliksen, M. S. (2015). Culture and Creativity: Examining Variations in Divergent Thinking within Norwegian and Canadian Communities. SAGE Open, 1-13. https://journals.sagepub.com/doi/pdf/10.1177/2158244015611448 https://doi.org/10.1177/2158244015611448

IBM (2010). IBM 2010 Global CEO Study: Creativity Selected as Most Crucial Factor for Future Success. https://www-03.ibm.com/press/us/en/pressrelease/31670.wss

Kaufman, J. C., \& Beghetto, R. A. (2009). Beyond Big and Little: The Four c Model of Creativity. Review of General Psychology, 13, 1-12. https://doi.org/10.1037/a0013688

Kim, H. H., Mishra, S., Hinds, P., \& Liu, L. (2012). Creativity and Culture: State of the Art. In H. Plattner, \& E. Al (Eds.), Design Thinking Research. (pp. 75-85). Berlin: Springer. https://doi.org/10.1007/978-3-642-21643-5_5

Kirton, M. A. (1989). Adaptors and Innovators: Styles of Creativity and Problem Solving. London: Routledge.

Klausen, S. H. (2010). The Notion of Creativity Revisited: A Philosophical Perspective on Creativity Research. Creativity Research Journal, 22, 347-360.

https://doi.org/10.1080/10400419.2010.523390

Lubart, T. (2010). Cross-Cultural Perspectives on Creativity. In J. C. Kaufman, \& R. J. Sternberg (Eds.), The Cambridge Handbook of Creativity (pp. 265-278). Cambridge, NY: Cambridge University Press. https://doi.org/10.1017/CBO9780511763205.017

Ludwig, A. M. (1992). Culture and Creativity. American Journal of Psychotherapy, 46, 454-469. https://doi.org/10.1176/appi.psychotherapy.1992.46.3.454

Mberu, B. U., \& Pongou, P. (2010). Nigeria: Multiple Forms of Mobility in Africa's Demographic Giant.

http://www.migrationpolicy.org/article/nigeria-multiple-forms-mobility-africas-demog raphic-giant

Mbiti, J. S. (1969). African Religions and Philosophy. Nairobi: East African Educational Publishers.

Mogaji, A. (2004). Review of Creativity in Nigeria. Unpublished Manuscript, Lagos: University of Lagos.

Mpofu, E., Myanbo, K., Mogaji, A. A., Mashego, T.-A., \& Khallefa, O. H. (2006). African Perspectives on Creativity. In J. C. Kaufman, \& R. J. Sternberg (Eds.), The International 
Handbook of Creativity (pp. 456-489). Cambridge, MA: Cambridge University Press. https://doi.org/10.1017/CBO9780511818240.016

Nabi, A. (2017). Language and Culture. Journal of Humanities and Social Sciences, 22, 91-94.

Niu, W., \& Kaufman, J. C. (2013). Creativity of Chinese and American Cultures: A Synthetic Analysis. The Journal of Creative Behavior, 47, 77-87.

https://doi.org/10.1002/jocb.25

Nwazuoke, A. I. (1989). Correlates of Creativity in High Achieving Nigerian Children. Ph.D. Thesis, Ilorin: University of Ilorin.

Obialo, F.-K. (2011). Psychosocial Factors as Correlates of Creativity among Undergraduates in Selected Southwestern Nigerian Universities. Ph.D. Thesis, Ibadan: University of Ibadan.

Obialo, F.-K. (2017a). The Transformative Power of Deliberate Creativity: Reflections of a Priest Creativity Practitioner. Master's Project. https://digitalcommons.buffalostate.edu/creativeprojects/265/

Obialo, F.-K. (2017b). Promoting Deliberate Creativity and Innovation in Nigerian Higher Education. East African Journal of Educational Research and Policy, 12, 58-73.

Obialo, F.-K. (2018). Teacher-Student Perception of Humour, Playfulness, and Creativity on Student Learning Outcome in Ibadan, Nigeria. Journal of Education, Society and Behavioural Science, 26, 1-13.

Olatoye, R. A., \& Oyundoyin, J. O. (2007). Intelligence Quotient as a Predictor of Creativity among Some Nigerian Secondary School Students. Educational Research and Review, 2, 92-95.

Oluseyi, A. D., \& Olujide, F.O. (2014). Education of the Gifted/Talented Students in Nigeria: A Justification. Journal of Education and Practice, 5, 9-11.

Onwubiko, O. A. (1991). African Thought, Religion \& Culture.

Pang, W., \& Plucker, J. A. (2013). Recent Transformations in China's Economic, Social, and Education Policies for Promoting Innovation and Creativity. The Journal of Creative Behavior, 46, 247-273. https://doi.org/10.1002/jocb.17

Puccio, G. (2012). Creativity as a Life Skill: at TEDxGramercy. https://www.youtube.com/watch?v=ltPAsp71rmI

Puccio, G. J., Cabra, J., \& Schwagler, N. (2018). Organizational Creativity: A Practical Guide for Innovators and Entrepreneurs. Los Angeles, CA: Sage Books.

Puccio, G. L., Mance, M., \& Murdock, M. C. (2011). Creative Leadership: Skills That Drive Change (2nd ed.). Los Angeles, CA: Sage Publications.

Rhodes, M. (1961). Analysis of Creativity. Phi Delta Kappan, 42, 305-310.

Rudowicz, E. (2003). Creativity and Culture: A Two Way Interaction. Scandinavian Journal of Educational Research, 47, 273-290. https://doi.org/10.1080/00313830308602

Runco, M. A. (2007). Creativity: Theories and Themes, Research, Development, and Practice. Amsterdam: Academy Press.

Runco, M. A., \& Albert, R. S. (2010). Creativity Research: A Historical View. In J. C. Kaufman, \& R. J. Sternberg (Eds.), The Cambridge Handbook of Creativity (pp. 3-19). New York: Cambridge University Press. https://doi.org/10.1017/CBO9780511763205.003

Smith, G. W. (2005). How Should Creativity Be Defined? Creativity Research Journal, 17, 293-295. https://doi.org/10.1207/s15326934cri1702\&3_14

Sternberg, R. J. (2003). The Propulsion Theory of Creative Contributions. In Wisdom, 
Intelligence and Creativity Crystallized (pp. 124-147). New York: Cambridge University Press.

Torrance, E. P. (2003). Reflection on Emerging Insights on the Educational Psychology of Creativity. In J. Houtz (Ed.), The Educational Psychology of Creativity (pp. 273-286). Cresskill, NJ: Hampton Press. https://doi.org/10.1017/CBO9780511509612.006

Yip, D. (2014). Enhancing Creativity through Multiculturalism. http://research.smu.edu.sg/news/smuresearch/2014/11/11/enhancing-creativity-throug $\underline{\text { h-multiculturalism }}$ 